\title{
SÍNDROME DE FLUJO VAGINAL (VAGINITIS / VAGINOSIS): ACTUALIZACIÓN DIAGNÓSTICA Y TERAPÉUTICA
}

\author{
VAGINAL DISCHARGE SYNDROME (VAGINITIS / VAGINOSIS): \\ DIAGNOSTIC AND THERAPEUTIC UPDATE
}

\author{
Franklin José Espitia De La Hoz ${ }^{a}$
}

\begin{abstract}
RESUMEN
Objetivo: actualizar el diagnóstico y la terapéutica en el síndrome de flujo vaginal (vaginitis / vaginosis), en mujeres gestantes y no gestantes. Materiales y métodos: se hizo una revisión sistemática y búsqueda bibliográfica de la literatura en diferentes bases de datos electrónicas, para identificar literatura relevante: Embase, Medline, Pubmed, entre otras, y libros de texto impresos; por medio de términos de búsqueda libres y estandarizados. Entre enero de 1991 y enero de 2021; sin restricción de idioma. Los comparadores incluyeron vaginosis bacteriana (VB), candidiasis vulvovaginal (CVV) e infección por Trichomonas vaginalis. Resultados: se incluyeron 93 estudios. La VB es la infección vaginal más prevalente (40-50\%) en mujeres en edad reproductiva, seguida por la CVV (20-25\%). La cándida albicans es la especie más prevalente (60,3\%); mientras que de las especies de Cándida no albicans, la Cándida tropicalis (9,9\%) y la Cándida glabrata $(12,2 \%)$ son las que prevalecen. La Gardnerella vaginalis es la causante del $19,5 \%$ de VB. La tricomoniasis vaginal es la Infección de Transmisión Sexual (no Viral) más común (0,8- 3,2 \%). Conclusiones: la VB es la infección vaginal más prevalente en mujeres en edad reproductiva, seguida de la CVV. La Cándida albicans es la especie más prevalente en la CVV mientras que la Gardnerella vaginalis predomina en la VB. Se requieren acciones de intervención urgentes que permitan mejorar las medidas de prevención de las infecciones vaginales, con el propósito de disminuir tanto la prevalencia como las complicaciones.
\end{abstract}

Palabras Clave: Excreción Vaginal; Leucorrea; Candidiasis Vulvovaginal; Vaginitis por Trichomonas; Vaginosis Bacteriana. (Fuente: DeCS BIREME).

\begin{abstract}
Objective: to update the diagnosis and therapy in vaginal discharge syndrome (vaginitis / vaginosis), in pregnant and non-pregnant women. Materials and methods: a systematic review and bibliographic search of the literature in different electronic databases was carried out to identify relevant literature: Embase, Medline, Pubmed, among others, and printed textbooks; by means of free and standardized search terms. Between January 1991 and January 2021; no language restriction. Comparators included bacterial vaginosis (BV), vulvovaginal candidiasis (CVV), and Trichomonas vaginalis infection.
\end{abstract}

Results: 93 studies were included. BV is the most prevalent vaginal infection (40-50\%) in women of reproductive age, followed by CVV (20-25\%). Candida albicans is the most prevalent species $(60.3 \%)$; while of the non-albicans Candida species, Candida tropicalis $(9.9 \%)$ and Candida glabrata $(12.2 \%)$ are the most prevalent. Gardnerella vaginalis is the cause of $19.5 \%$ of BV. Vaginal trichomoniasis is the most common Sexually Transmitted (Non-Viral) Infection (0.8-3.2\%). Conclusions: BV is the most prevalent vaginal infection in women of reproductive age, followed by CVV. Candida albicans is the most prevalent species in CVV while Gardnerella vaginalis predominates in BV. Urgent intervention actions are required to improve vaginal infection prevention measures, in order to reduce both the prevalence and complications.

Key Words: Vaginal Discharge; Leukorrhea; Candidiasis, Vulvovaginal; Trichomonas Vaginitis; Vaginosis, Bacterial. (Source: MeSH NLM)).

\section{INTRODUCCIÓN}

El síndrome de flujo vaginal o vaginitis es un proceso infeccioso vaginal caracterizado por la siguiente sintomatología: flujo vaginal, ardor, fetidez, irritación, prurito vulvar, dispareunia y disuria, secundario a infecciones (exógenas o endógenas) bacterianas, fúngicas y/o parasitarias; como consecuencia de un desequilibrio ambiental en el ecosistema vaginal ${ }^{1,2}$.

\footnotetext{
a. Ginecología y Obstetricia / Universidad Militar nueva Granada

Sexología Clínica - Master en sexología: educación y asesoramiento sexual / Universidad de Alcalá de Henares

Uroginecología / FUCS - Hospital de San José / Unicamp, Brasil.

Director científico: Hathor, Clínica Sexológica
} 
En las mujeres que buscan atención médica, alrededor del $11-38,4 \%$ está asociada a síntomas relacionados con el síndrome de flujo vaginal (vaginitis), siendo la vaginosis bacteriana (VB), la candidiasis vulvovaginal (CVV) y la infección por Trichomonas vaginalis (TV), las infecciones más comunes en mujeres en edad reproductiva ${ }^{3,4}$.

Es usual que se convierta en un desafío distinguir entre un flujo anormal y uno normal, tanto desde la perspectiva de la paciente como del profesional de la salud; la diferencia radica en que las variaciones fisiológicas normales se producen debido a cambios biológicos u hormonales ${ }^{5,6}$.

La VB es responsable del 40-50\% de los casos del síndrome de flujo vaginal (vaginitis), seguido de la CVV con el $20-25 \%$ y la TV con el $15-20 \%$ de los casos ${ }^{7}$.

La mayoría de las mujeres tienen al menos un episodio de vaginitis durante su vida ${ }^{8}$, convirtiéndose en el diagnóstico ginecológico más común en la atención primaria.

La vaginitis ejerce un efecto negativo en la calidad de vida de las mujeres, generándoles ansiedad, vergüenza y preocupaciones sobre la higiene ${ }^{9,10}$.

La historia clínica por sí sola no es suficiente para hacer el diagnóstico de las diferentes causas de vaginitis; los hallazgos del examen físico y los resultados de las ayudas diagnosticas pueden usarse junto con la historia clínica para determinar el diagnóstico ${ }^{11}$.

Los regímenes terapéuticos de la vaginitis son múltiples, siendo necesario tener en cuenta tanto la infección recurrente como la presencia de efectos adversos, de igual manera no olvidar la resistencia, la diferencia durante el embarazo y el tratamiento de las parejas sexuales ${ }^{7,12}$.

La CVV no complicada se trata de forma más eficaz con azoles locales. El tratamiento oral con una sola dosis de fluconazol también es eficaz. El tratamiento de la CVV complicada es prolongado y con mayor frecuencia consiste en dosis múltiples de fluconazol oral o al menos una semana de azoles locales ${ }^{7,10,12}$.

El pilar de la terapia contra la VB es el metronidazol, pero también se han utilizado con éxito nitroimidazoles y algunos otros agentes, como el nifuratel ${ }^{3,6,9}$.

En la TV el metronidazol ha sido el tratamiento de elección para las mujeres durante décadas, y la dosis única se ha considerado la primera línea de tratamiento; con una resistencia del $2-5 \%$, y fracaso terapéutico del $7-10 \%^{1,3,6}$.

El objetivo de esta revisión consistió en evaluar la más actualizada información diagnóstica y terapéutica acerca del síndrome de flujo vaginal (vaginitis / vaginosis), en mujeres gestantes y no gestantes; a fin de ofrecerles a los profesionales de la salud las más recientes pautas para el abordaje diagnóstico y terapéutico de esta frecuente condición clínica.

\section{MATERIALES Y MÉTODOS}

La pregunta definitiva de investigación de esta revisión describe el síndrome de flujo vaginal (vaginitis / vaginosis). Se tuvieron en cuenta los siguientes criterios de inclusión: Tipo de estudios: ensayos clínicos aleatorizados fase III, publicados entre el 01 de enero de 1991 y el 31 de enero de 2021; sin restricción de idioma, pero que ofrecieran disponibilidad del texto completo para su evaluación total. Tipo de población: estudios que incluyeran mujeres en edad reproductiva, con infecciones vaginales o síndrome de flujo vaginal (vaginitis / vaginosis).

Tipo de intervención: La tecnología de interés fue síndrome de flujo vaginal (vaginitis / vaginosis) o infecciones vaginales; los comparadores destacan vaginosis bacteriana (VB), candidiasis vulvovaginal (CVV) e infección por Trichomonas vaginalis (TV); así como el diagnóstico y tratamiento.

Estrategia de búsqueda: Se hizo una revisión sistemática y búsqueda bibliográfica de la literatura en diferentes bases de datos electrónicas, mediante las siguientes bases de datos: Cinhal Plus, Cochrane Central Register of Controlled Trials (CENTRAL) (plataforma Ovid), Cochrane Database of Systematic Reviews (plataforma Wiley), Data-base of Abstracts of Reviews of Effects (DARE) (plataforma Wiley), EMBASE (Elsevier), Lilacs (Biblioteca Virtual en Salud - BVS, interfaz iAHx), Medline vía PubMed, Scopus, WHO International Clinical.

Términos clave de la búsqueda: Los criterios que definieron la población a manera de texto libre y vocabulario controlado (MeSH, Emtree y DeCS) fueron: "Vaginal Discharge", "Leukorrhea" [Mesh] y "Vaginitis". Los términos para las tecnologías de salud de interés, que se asociaron mediante el operador booleano odds ratio (OR), fueron: "Candidiasis, Vulvovaginal", "Vaginosis, Bacterial" y "Trichomonas Vaginitis". Al final, los términos de búsqueda que definieron la población se unieron con los términos de las tecnologías de salud de interés mediante el operador booleano "AND". Los términos de búsqueda utilizados se ajustaron según la plataforma de búsqueda de cada base de datos electrónica. Por otro lado, se hizo una búsqueda manual en "bola de nieve" a partir de la lista de referencias de cada artículo seleccionado.

Aspectos éticos: Al tratarse de una revisión de literatura se considera una investigación sin riesgo. 


\section{RESULTADOS}

La búsqueda en las bases de datos arrojó un total de 524 referencias, al desechar los duplicados quedaron un total de 271 referencias; de las cuales se seleccionaron 93 que cumplían criterios de inclusión según título, resumen y abstract para poder evaluarlas en texto completo. La mayoría de los estudios incluyeron una población de mujeres jóvenes con edades entre 18 y 42 años.

La mayoría de las mujeres tienen secreciones vaginales, ya sean fisiológicas o patológicas; el desafío para el médico consiste en separar las infecciones vaginales que puedan provocar alteraciones en la mujer ${ }^{13}$. El síndrome de flujo vaginal o vaginitis / vaginosis es una inflamación de la vulva, la vagina o ambas, generalmente acompañada de flujo vaginal anormal ${ }^{1,2}$.

Las secreciones vaginales normales contienen agua, electrolitos, células epiteliales, organismos microbianos, ácidos grasos y compuestos de carbohidratos ${ }^{12-14}$. La concentración de bacterias anaerobias suele ser cinco veces mayor que la de los organismos aeróbicos. Los organismos más prevalentes en la vagina son los lactobacilos, estreptococos, Staphylococcus epidermidis, Gardnerella vaginalis y Escherichia coli. Las especies anaeróbicas que se aíslan con frecuencia incluyen Peptostreptococcus, Lactobacillus anaerobios y Bacteroides spp $\mathrm{p}^{12,14}$.

El pH vaginal, el contenido de glucógeno y la cantidad de secreción influyen en la cantidad y el tipo de organismos presentes en la vagina. Los lactobacilos restringen el crecimiento de otros organismos al producir ácido láctico, manteniendo así un $\mathrm{pH}$ bajo. Estos organismos también producen peróxido de hidrógeno, que es tóxico para los anaerobios. La población bacteriana vaginal normal ayuda a inhibir el crecimiento de organismos vaginales patológicos. Si se altera la microbiota vaginal normal, existe una mayor posibilidad de proliferación de organismos patógenos. El desafío del tratamiento de la vaginitis durante el embarazo es la necesidad de realizar un diagnóstico preciso y tratarlo correctamente $e^{1,3,6,12}$.

\section{Epidemiologia}

En la diaria práctica médica, las infecciones vaginales representan un frecuente problema de salud; siendo la vaginosis bacteriana (VB), la candidiasis vulvovaginal (CVV) y la tricomoniasis vaginal (TV), las tres infecciones más frecuentemente asociadas al síndrome de flujo vaginal ${ }^{7,13}$. En una misma mujer pueden coexistir más de una forma clínica (vaginitis y/o vaginosis); y si el examen ginecológico no permite afirmar la presencia de un agente causal en particular, el tratamiento deberá ser enfocado de forma sindrómica.
Los estudios, en los cuales se incluyeron diferentes estratos socioeconómicos, informan que la prevalencia de flujo vaginal anormal es del 12,1$30 \%{ }^{15,16}$. La vaginosis bacteriana (VB), la candidiasis vulvovaginal (CVV) y la infección por Trichomonas vaginalis (TV) son comunes en mujeres en edad reproductiva; el $34 \%$ representa la VB, 30\% CVV y el $7 \%$ TV $^{15-17}$.

\section{Candidiasis vulvovaginal (CVV)}

La candidiasis vulvovaginal (CVV) es una causa común de flujo vaginal en todo el mundo ${ }^{2,10,12}$; aproximadamente el $75 \%$ de las mujeres experimentarán un episodio a lo largo de su vida reproductiva, el 5\% tendrá episodios infecciosos recurrentes con un $15 \%$ de infección mixta; un $45 \%$ ha presentado 2 o más episodios; y entre el 10 $20 \%$ son complicadas; el pico máximo de su incidencia ocurre entre los 20 y 40 años $^{7,17,18}$.

La CVV es causada por el hongo, Cándida spp. (albicans, tropicalis, pseudotropicalis, krusei, stellaloidea, torulopsis, glabrata y rhodotromla). La Cándida albicans representa entre el $80-90 \%$ de las infecciones vaginales producidas por hongos ${ }^{17,18}$; otras especies menos frecuentes son la Cándida Glabrata, Tropicalis y Krusei, que representan alrededor del $10 \%{ }^{18-20}$.

La patogenia de la CVV implica tres pasos consecutivos: la adherencia seguida de la invasión de las células epiteliales, la formación de la biopelícula y la secreción de factores de virulencia (figura 1).

Manifestaciones clínicas: La candidiasis es una verdadera vaginitis inflamatoria, cursa con prurito, disuria externa y dispareunia introital, usualmente acompañada de leucorrea. El flujo lo caracteriza una secreción blanca, grumosa y adherente a las paredes vaginales (típicamente como "requesón"); la mucosa vaginal se observa visiblemente enrojecida ${ }^{21,22}$.

Factores de riesgo: Existe una multiplicidad de factores de riesgo, algunos son propios del huésped y otros están asociados a su comportamiento. El crecimiento del hongo en el tracto genital femenino está regulado por la microbiota residente (Lactobacillus spp.). Los factores predisponentes incluyen: embarazo, diabetes mellitus, terapia inmunosupresora (fármacos citotóxicos, esteroides, etc.), uso de antibióticos, anticonceptivos orales, enfermedades inmunodeficientes $(\mathrm{VIH}$, cáncer, enfermedad crónica, etc.), ropa interior ajustada y/o de nailon $23-25$. El calor y la humedad favorecen el crecimiento de la Cándida spp (26); y aunque no se considera una infección de transmisión sexual, puede transmitirse sexualmente; de hecho, varios estudios informan de una asociación entre la candidiasis y el sexo orogenital ${ }^{17,27}$. 


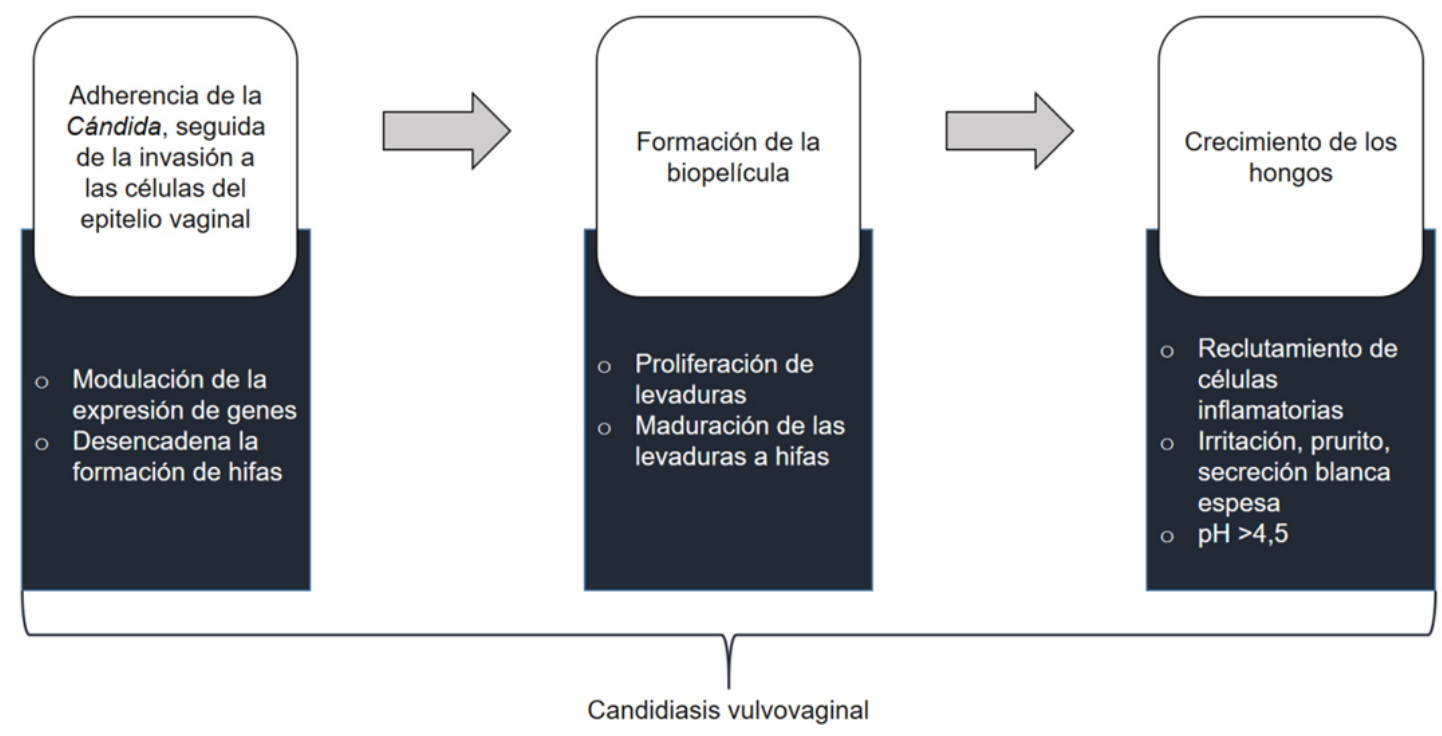

Figura 1. Vía implicada en la patogenia de la candidiasis vulvovaginal (CVV), ‘*’ indica síntomas clínicos de CVV.

Diagnóstico: El diagnóstico de la CVV puede hacerse a través de la inspección visual, $\mathrm{pH}$ vaginal, microscopía, Papanicolaou, prueba de látex y cultivo de la secreción cervicovaginal ${ }^{28,29}$.

La mayoría de las pacientes se quejan de leucorrea; pero la dispareunia, el prurito vulvar y el ardor son los síntomas principales ${ }^{19}$. Las mujeres además suelen referir prurito y ardor después del coito o al orinar. En la exploración física se puede observar eritema y edema de los labios mayores y menores y erupciones en el perineo y los muslos, con leucorrea blanquecina, espesa en forma de cuajada, similar al queso cottage $e^{2,19}$

En presencia de un síndrome de flujo vaginal por hongos (vaginitis), el pH vaginal normal $(<4,5)$ descarta la vaginosis y orienta la exploración de hongos. Si el $\mathrm{pH}$ es mayor a 4,5 sugiere vaginosis bacteriana, tricomoniasis o endocervicitis mucopurulenta ${ }^{12,20,24}$.

La microscopía con $\mathrm{KOH}$ (hidróxido de potasio) o $\mathrm{NaOH}$ (hidróxido de sodio), puede evidenciar la presencia de pseudohifas o micelios. La presencia de blastosporas o pseudohifas de levadura se detectan en aproximadamente el 30-50\% de las pacientes con CVV sintomática. La cándida spp también puede evidenciarse en frotis de las secreciones cervicovaginales con la coloración del Papanicolaou ${ }^{30,31}$.

La aglutinación de partículas de látex (en inglés, Latex particle agglutination, LPA) es más sensible $(82 \%)$ que la microscopía de $\mathrm{KOH}^{32}$ y más específica que otros criterios de diagnóstico ${ }^{33}$; sin embargo, puede presentar falsos positivos ${ }^{34}$, especialmente en mujeres asintomáticas, o una sensibilidad menor que la del examen microscópico de $\mathrm{KOH}$ realizado por profesionales experimentados ${ }^{35}$.

La prueba de inmunocromatografía sensible (en inglés, immunochromatography test, ICT), el CandiVagi, es útil para el diagnóstico rápido de la CVV utilizando un anticuerpo monoclonal (MAb), inmunoglobulina $M$ ( $\lg \mathrm{M})$ dirigido contra el manano de Candida $\mathrm{spp}^{36}$.

La CVV suele clasificarse en: no complicada, complicada (tabla 1), recurrente y por especies resistentes ${ }^{37}$.

Tabla 1. Clasificación de la Candidiasis Vulvovaginal

\begin{tabular}{lll}
\hline Características & \multicolumn{1}{c}{ No complicada } & Complicada \\
\hline Frecuencia & Episodios esporádicos e infrecuentes & Episodios recurrentes ( $\geq 4$ por año) \\
Intensidad & Síntomas leves a moderados & Síntomas severos \\
Especies & Sospecha de infección por & Sospecha de infección por \\
Cándida Albicans & Cándida no Albicans
\end{tabular}


Tratamiento: El propósito del tratamiento de la CVV consiste en aliviar la sintomatología y evitar sus potenciales complicaciones; de tal manera que se debe tratar a todas las pacientes sintomáticas $(\text { tabla } 2)^{39}$.

En la CVV no complicada los resultados con tratamientos tópicos con derivados imidazólicos, poliénicos o piridinona de corta duración, suelen ser buenos $^{39,40}$ (tabla 3 ).
Recurrente: Definida como 4 o más episodios por año. Tiene una prevalencia que oscila entre el 8-10\%. En comparación con las mujeres sin antecedentes de CVV, las mujeres con CVV recurrente (CVVr) informan una calidad de vida significativamente más baja, así como menor satisfacción con la salud, el bienestar físico y psicológico y una disminución de la satisfacción con el hogar y el entorno laboral ${ }^{31,33}$. En el manejo de la CVVr es necesario un tratamiento a largo plazo durante varios meses, a fin de evitar más recurrencias ${ }^{17}$.

Tabla 2. Tratamiento de la Candidiasis Vulvovaginal complicada

\section{Candidiasis Vulvovaginal recurrente}

Regímenes iniciales:

7 a 14 días de cualquier fármaco azólico tópico ó

100, 150 o 200 mg de fluconazol, vía oral, una vez al

día cada tres días para un total de 3 dosis (día 1, 4 y 7 )

\section{Candidiasis Vulvovaginal severa}

Por vía intravaginal una vez al día durante 7 a 14 días de cualquier fármaco azólico tópico ó

150 mg de fluconazol, vía oral, una vez al día, en dos dosis (segunda dosis 72 horas después de la dosis inicial)

\section{Candidiasis Vulvovaginal por Cándida no Albicans}

Azol sin fluconazol (oral o tópico)

De 7 a 14 días

ó Cápsula de gelatina de ácido bórico Vía intravaginal una vez al día durante 14 días

Alternativa:

Nifuratel (500 mg) - nistatina (200.000 UI)

Un óvulo intravaginal, una vez en la noche, al acostarse a dormir (durante 12 días)

Tabla 3. Tratamiento de la Candidiasis Vulvovaginal no complicada

\begin{tabular}{|c|c|}
\hline Agentes intravaginales de venta libre & Agentes intravaginales recetados \\
\hline $\begin{array}{l}\text { Butoconazol Crema al } 2 \% ; 5 \text { g vía intravaginal } \\
\text { durante } 3 \text { días } \\
\text { ó }\end{array}$ & $\begin{array}{l}\text { Butoconazol Crema al } 2 \% \\
\text { (dosis única vía intravaginal durante } 1 \text { día } \\
\text { ó }\end{array}$ \\
\hline $\begin{array}{l}\text { Clotrimazol Crema al 1\%; } 5 \text { g vía intravaginal } \\
\text { durante } 7 \text { a } 14 \text { días } \\
\text { ó }\end{array}$ & $\begin{array}{l}\text { Nistatina, tableta vaginal de } 100.000 \text { unidades, } \\
\text { una tableta durante } 14 \text { días } \\
\text { ó }\end{array}$ \\
\hline $\begin{array}{l}\text { Clotrimazol Crema al } 2 \% ; 5 \text { g vía intravaginal } \\
\text { durante } 3 \text { días } \\
\text { ó }\end{array}$ & $\begin{array}{l}\text { Terconazol Crema al } 0,4 \% ; 5 \text { g vía intravaginal } \\
\text { durante } 7 \text { días } \\
\text { ó }\end{array}$ \\
\hline $\begin{array}{l}\text { Miconazol Crema al 2\%; } 5 \text { g vía intravaginal } \\
\text { durante } 7 \text { días } \\
\text { ó }\end{array}$ & $\begin{array}{l}\text { Terconazol Crema al 0,8\%; } 5 \text { g vía intravaginal } \\
\text { durante } 3 \text { días } \\
\text { ó }\end{array}$ \\
\hline $\begin{array}{l}\text { Miconazol Crema al } 4 \% ; 5 \text { g vía intravaginal } \\
\text { durante } 3 \text { días } \\
\text { ó }\end{array}$ & $\begin{array}{l}\text { Terconazol supositorio vaginal } 80 \text { mg; } \\
80 \text { mg intravaginal durante } 3 \text { días }\end{array}$ \\
\hline \multicolumn{2}{|l|}{$\begin{array}{l}\text { Miconazol supositorio, } 100 \text { mg vía vaginal, } \\
\text { durante } 7 \text { días } \\
\text { ó }\end{array}$} \\
\hline \multicolumn{2}{|l|}{$\begin{array}{l}\text { Miconazol supositorio, } 200 \text { mg vía vaginal } \\
\text { durante } 3 \text { días } \\
\text { ó }\end{array}$} \\
\hline \multicolumn{2}{|l|}{$\begin{array}{l}\text { Miconazol supositorio, 1,200 mg vía vaginal, } \\
\text { durante } 1 \text { día } \\
\text { ó }\end{array}$} \\
\hline $\begin{array}{l}\text { Tioconazol pomada al } 6,5 \% ; 5 \text { g vía intravaginal } \\
\text { en una sola aplicación }\end{array}$ & \\
\hline
\end{tabular}


Complicaciones: si no se trata, lo más probable es que la CVV empeore y cause rotura prematura de membranas, trabajo de parto prematuro, corioamnionitis y candidiasis cutánea congénita (entre las gestantes); además, puede contribuir al incremento de la susceptibilidad a la infección por $\mathrm{VIH}$, candidiasis invasiva e infecciones secundarias (debido al rascado) ${ }^{37-39}$.

\section{Vaginosis bacteriana (VB)}

La vaginosis bacteriana (VB) es la causa más frecuente de infección vaginal. Representa una disbiósis o disbacteriosis (alteración en la composición y/o funciones de los microorganismos que habitan la vagina), debido a la alteración de la flora vaginal dominante por un desorden del ecosistema, caracterizado por un cambio en la flora vaginal y ausencia de la flora de lactobacilos, con predominio de diversas bacterias anaerobias, que incluyen una película polimicrobiana de estructura densa, constituida principalmente por Gardnerella vaginalis y Atopobium vaginae fuertemente adheridos al epitelio vaginal; Mycoplasma hominis, Ureaplasma urealyticum y otros anaerobios y bacterias aerobias facultativas, como Prevotella, Mobiluncus, Bacteroides, Clostriadiales y Peptostreptococcus ${ }^{41-43}$.

La vaginosis bacteriana cursa de forma asintomática entre $11-48 \%$ de los $\operatorname{casos}^{44}$. Su prevalencia varía según la raza, la edad y las condiciones sociodemográficas; pero usualmente se registra más allá del $29,2 \%{ }^{45}$, siendo mayor en el grupo de mujeres en edad reproductiva. La prevalencia varía del 4,9$35 \%$ en los países de ingresos altos y del $20-51 \%$ en los países de ingresos bajos y medios ${ }^{44,45}$.
La patogenia de la VB es un estado disbiótico caracterizado por deficiencia de bacterias productoras de ácido láctico y suficiencia de diversidad bacteriana anaeróbica (figura 2).

Manifestaciones clínicas: Secreción vaginal abundante de color blanco-grisáceo con "olor a pescado", más notoria luego del coito sin protección o en los periodos de menstruación. El eritema de las mucosas normalmente no es una característica; pero usualmente alrededor del $50 \%$ de las pacientes cursan de forma asintomática ${ }^{46}$.

Factores de riesgo: Las conductas que favorecen la aparición de la VB destacan: 1) inicio precoz de las relaciones sexuales, 2) múltiples parejas sexuales masculinas y una o más femeninas en los últimos 12 meses, 3) uso inestable del condón y 4) práctica del sexo oral (del hombre hacia la mujer o entre mujeres), mala higiene intima, uso de dispositivos intrauterinos (DIU), estado inmunitario deficiente, empleo de duchas vaginales, tabaquismo, Infecciones vaginales concomitantes, uso de antibióticos, bajo estrato socioeconómico, embarazo, patología genital, sangrado uterino anormal, entre otros ${ }^{47,48}$.

Diagnóstico: Se puede hacer mediante la aplicación de criterios clínicos, o a través de la evaluación de los morfotipos bacterianos presentes en el Gram de la secreción vaginal ${ }^{49}$. Los métodos más utilizados incluyen los criterios de $\mathrm{Amsel}^{50}$ (tabla 4), y los criterios de Nugent ${ }^{51}$ (tabla 5).

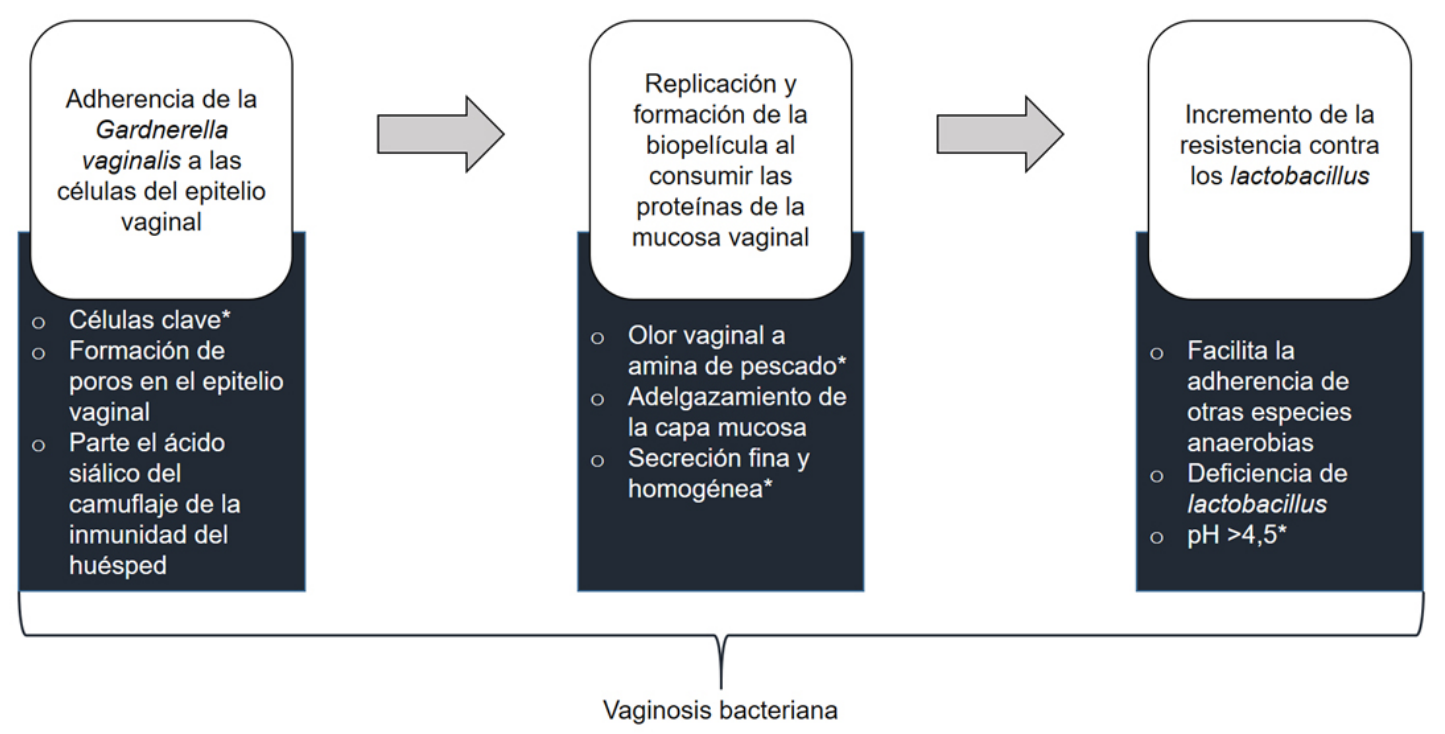

Figura 2. Vía implicada en la patogenia de la vaginosis bacteriana, ‘*' indica cuatro síntomas clínicos de VB descritos por los criterios de Amsel. 
Tabla 4. Criterios de Amsel para el diagnóstico de la vaginosis bacteriana

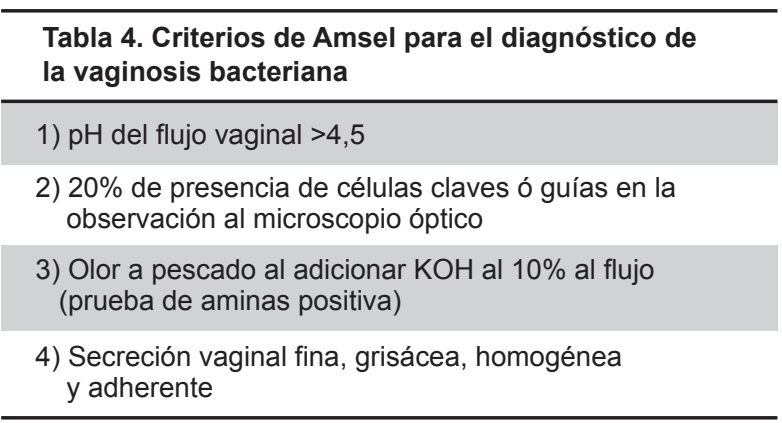

Diagnóstico: Se puede hacer mediante la aplicación de criterios clínicos, o a través de la evaluación de los morfotipos bacterianos presentes en el Gram de la secreción vaginal49. Los métodos más utilizados incluyen los criterios de Amsel50 (tabla 4), y los criterios de Nugent51 (tabla 5).

La presencia de al menos tres de los criterios de Amsel, son diagnósticos de la VB. La sensibilidad y especificidad varían del $37-70 \%$ y del $94-99 \%$, respectivamente ${ }^{52,53}$.

En los criterios de Nugent el desequilibrio en la microbiota vaginal se evalúa mediante la cuantificación de cuatro morfotipos bacterianos, en el examen directo de la secreción vaginal teñido con Gram: bacilos Gram positivos largos (Lactobacillus spp.); cocobacilos Gram variables o gramnegativos (Gardnerella vaginalis), bacilos curvos Gram negativos (Mobiluncus spp.) y bacilos Gram negativos tipo Bacteroides spp. La elevada especificidad y sensibilidad que han demostrado los criterios de Nugent, los han convertido en la técnica de elección (estándar de oro) en la detección de la vaginosis bacteriana (tabla 5).

La interpretación de los criterios de Nugent está basada en la puntuación final, luego de sumar las cruces de los morfotipos de las bacterias presentes: 0 a 3 se considera flora normal; 4 a 6 puntos considera flora intermedia o mixta; 7 a 10 puntos es diagnóstico de vaginosis bacteriana ${ }^{54}$.

Los cultivos no son confiables ante la falta de especificidad, dado que se trata de una infección polimicrobiana, por lo tanto, no se recomiendan ${ }^{7}$.

OSOM BV Azul. El OSOM BV Blue assay (Genzyme Diagnostics, Cambridge, MA) es una prueba cromogénica (point-of-care test (POCT)), la cual mide los niveles de sialidasa en el fluido vaginal. Las sialidasas, antes conocidas como neuraminidasas, son producidas por bacterias como las especies Gardnerella y Bacteroides. La prueba es una tira reactiva y los resultados están disponibles en 10 minutos. La sensibilidad y especificidad varían de 88$94 \%$ y de $91-98 \%$, respectivamente, en comparación con los criterios de Nugent y Amsel ${ }^{54,55}$.

Tarjeta FemExam. El POCT FemExam (Cooper Surgical, Shelton, CT) detecta productos metabólicos de la Gardnerella vaginalis, que incluyen aminas y la actividad de la prolina aminopeptidasa, y mide el $\mathrm{pH}$ vaginal. Consta de dos tarjetas de plástico; una tarjeta es para la medición del $\mathrm{pH}$ y la presencia de trimetilamina, y la segunda es para la medición de prolina aminopeptidasa. La sensibilidad combinada de las tarjetas 1 y 2 es del $91 \%$ y la especificidad del $61 \%$ en comparación con la puntuación de Nugent. Es muy rápido (los resultados están disponibles 2 minutos), objetivo y fácil de realizar ${ }^{56}$.

Las técnicas de amplificación de ácidos nucleicos (del inglés, Nucleic acid amplification tests (NAATs)), como la $\mathrm{PCR}$, son teóricamente capaces de detectar tan solo un organismo en una muestra; sin embargo, no hay evidencia de su superioridad clínica sobre los criterios de Amsel y de Nugent, ni han demostrado ser de ayuda para orientar la terapia, además son costosas ${ }^{57,58}$.

Tabla 5. Criterios de Nugent para el diagnóstico de la vaginosis bacteriana

Tabla 5. Criterios de Nugent para el diagnóstico de la vaginosis bacteriana

\begin{tabular}{cccc}
\hline Puntuación & $\begin{array}{l}\text { Lactobacillus } \\
\text { (bacilos Gram positivos) }\end{array}$ & $\begin{array}{l}\text { Gardnerella y Bacteroides spp. } \\
\text { (bacilos y cocobacilos } \\
\text { Gram negativos }\end{array}$ & $\begin{array}{l}\text { Mobiluncus (bacilos } \\
\text { Gram negativos curvos) }\end{array}$ \\
\hline 0 & $4+$ & 0 & 0 \\
1 & $3+$ & $1+$ & $2+$ \\
2 & $2+$ & $3+$ & $3+$ ó $2+$ \\
3 & $1+$ & $4+$ & $3+$ \\
\hline
\end{tabular}

0 : no morfotipos presentes; $1+:<1$ morfotipo presente; $2+: 1$ - 4 morfotipos presentes;

$3+: 5-30$ morfotipos presentes; $4+: 30$ ó más morfotipos presentes. 
En síntesis, existe una amplia variedad de pruebas diagnósticas disponibles para realizar el diagnóstico de la vaginosis bacteriana, que van desde el POCT hasta ensayos moleculares. Los médicos deberán considerar los costos, el tiempo de los resultados y la precisión en su decisión de seleccionar una prueba diagnóstica, especialmente en mujeres sintomáticas, ya que no existen recomendaciones para la detección de vaginosis bacteriana en mujeres asintomáticas ${ }^{46}$.

Tratamiento: La biopelícula polimicrobiana muestra una alta resistencia a los mecanismos protectores de la microflora vaginal normal59, así como una mayor tolerancia a los antibióticos ${ }^{60}$; por lo tanto, las biopelículas vaginales juegan un papel clave no solo en la patogénesis de la VB, sino también en el fracaso del tratamiento y la recurrencia ${ }^{59,60}$.

La terapia con antibióticos es el pilar del tratamiento de la VB. En la tabla 6 se detalla una lista de regímenes recomendados por los Centros para el Control y la Prevención de Enfermedades de los Estados Unidos (Centers for Disease Control and Prevention) ${ }^{7}$. Hasta un $15 \%$ de las pacientes no responden al tratamiento antimicrobiano inicial, y las tasas de recurrencia entre las respondedoras siguen siendo significativas altas $(80 \%)$, por lo que requieren la administración repetida de antibióticos ${ }^{61,62}$.

Las terapias de elección para la VB son metronidazol y clindamicina sistémicos o tópicos. Los estudios informan tasas de curación del 70-96\% para ambos antibióticos, con tasas de recurrencia del 49-66\%, después de 7 días de tratamiento ${ }^{61,62}$. El diagnóstico inadecuado, la resistencia farmacológica y la persistencia de una biopelícula bacteriana adherente después del tratamiento, han sido responsabilizadas de ser las principales razones de los fracasos terapéuticos ${ }^{60}$.
Complicaciones: Se asocia con la prematuridad y bajo peso al nacer, enfermedad inflamatoria pélvica, infertilidad, adquisición del VIH y el virus del herpes simple tipo 2 (VHS-2) e infecciones secundarias ${ }^{48,49,62}$.

\section{Tricomoniasis vaginal (TV)}

La Trichomonas vaginalis, también conocida como tricomoniasis, se presenta como una vaginitis, caracterizando una forma común de cervico-vaginitis inflamatoria causada por el parásito flagelado unicelular (Trichomonas vaginalis). Es la infección de transmisión sexual (ITS) no Viral, más común y curable, extendida en el mundo entero ${ }^{63,64}$.

La TV suele ocurrir durante los años reproductivos. Se encuentra asociada con frecuencia a otras ITS, coexistiendo en muchas ocasiones con infección concomitante por Chlamydia trachomatis, Gardnerella Vaginalis y Neisseria gonorrhoeae. El ser humano es el único huésped natural de la TV ${ }^{63-65}$.

La prevalencia de la tricomoniasis vaginal varía de una región a otra, dependiendo de la cultura, la población y el momento en que se estudie, entre otras; estimándose entre $3-74 \%$ en mujeres y entre $5-29 \%$ en hombres ${ }^{66}$. La OMS (Organización Mundial de la Salud) registró 276,4 millones de nuevos casos en el año 2008, para un incremento de $11,2 \%$ con respecto al año 2005 ( $n=248,5$ millones de casos) y para el continente americano, registró una incidencia de 85,4 millones de casos y una prevalencia de 57,8 millones ${ }^{67}$.

El paso inicial en la patogenia de la tricomoniasis es la adhesión a las células epiteliales vaginales a través del sitio opuesto de la membrana ondulante (figura 3).

Tabla 6. Tratamientos recomendados para vaginosis bacteriana

\begin{tabular}{|c|c|}
\hline Tres regímenes recomendados & Tres regímenes alternativos \\
\hline $\begin{array}{l}\text { Metronidazol } 500 \text { mg, vía oral, dos veces al } \\
\text { día durante } 7 \text { días }\end{array}$ & $\begin{array}{l}\text { Tinidazol } 2 \text { gramos, vía oral una vez al día } \\
\text { durante } 2 \text { días }\end{array}$ \\
\hline $\begin{array}{l}\text { Metronidazol } \mathrm{Gel} \text { al } 0,75 \%, 1 \text { aplicación } \\
\text { completa }(5 \mathrm{~g}) \text {, vía intravaginal, una vez } \\
\text { al día durante } 5 \text { días }\end{array}$ & $\begin{array}{l}\text { Tinidazol } 1 \text { gramos, vía oral, una vez al día } \\
\text { durante cinco días }\end{array}$ \\
\hline \multirow{2}{*}{$\begin{array}{l}\text { Clindamicina Crema al 2\%, } 1 \text { aplicación } \\
\text { completa }(5 \mathrm{~g}) \text {, vía intravaginal al acostarse } \\
\text { durante } 7 \text { días }\end{array}$} & $\begin{array}{l}\text { Clindamicina } 300 \text { mg, vía oral, dos veces } \\
\text { al día durante } 7 \text { días }\end{array}$ \\
\hline & $\begin{array}{l}\text { Clindamicina Óvulos de } 100 \text { mg, } \\
\text { vía intravaginal, una vez al acostarse } \\
\text { durante } 3 \text { días }\end{array}$ \\
\hline \multicolumn{2}{|c|}{$\begin{array}{l}\text { Alternativa: } \\
\text { Nifuratel ( } 500 \mathrm{mg}) \text { - nistatina (200.000 UI) } \\
\text { Un óvulo intravaginal, una vez en la noche, al acostarse a dormir (durante } 6 \text { días) }\end{array}$} \\
\hline
\end{tabular}




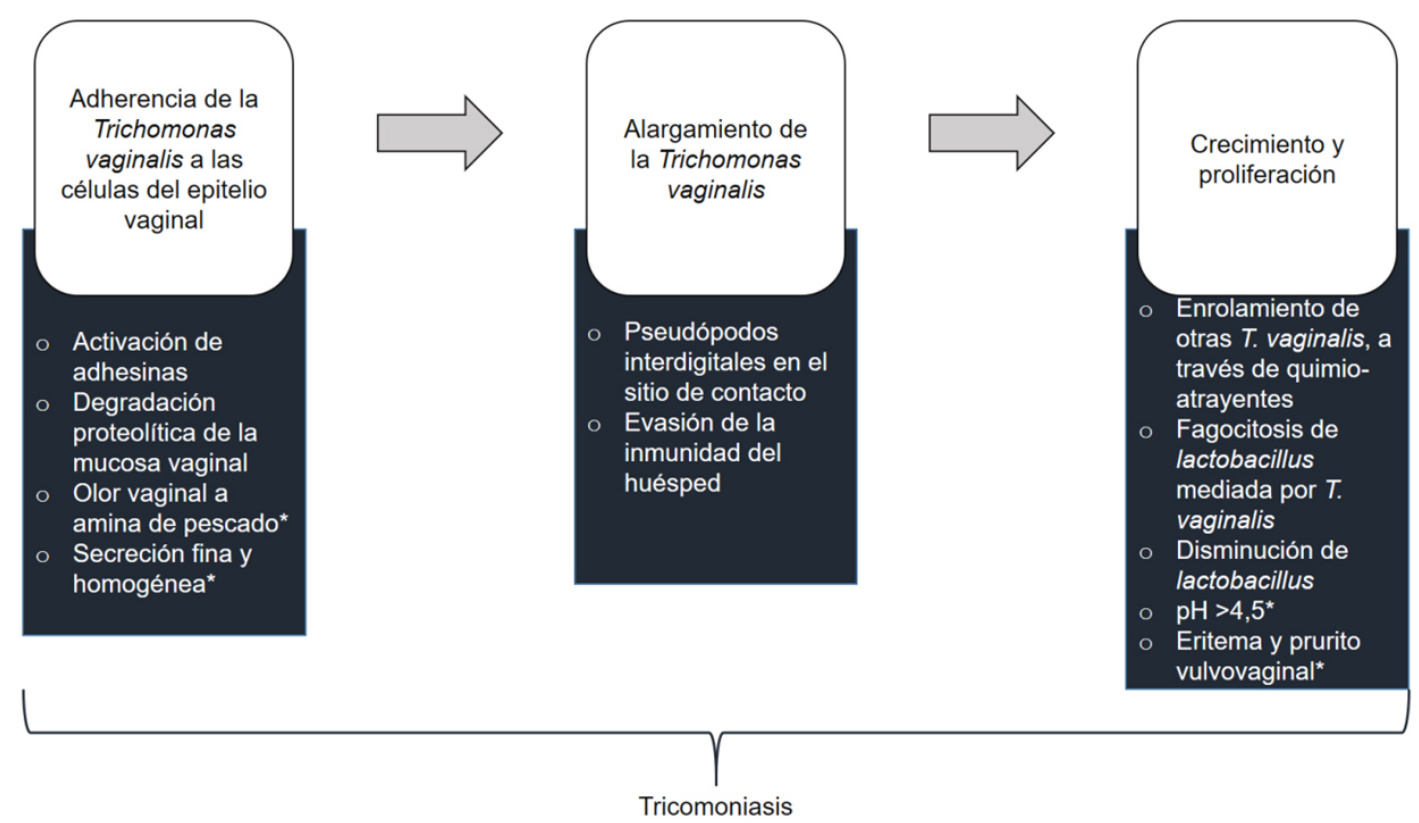

Figura 3. Vía implicada en la patogenia de la tricomoniasis, ‘*’ indica síntomas clínicos de TV

Manifestaciones clínicas: La mayoría de las personas infectadas son asintomáticas o presentan síntomas inespecíficos. La sintomatología de la TV es más frecuente y acentuada en presencia de incremento del $\mathrm{pH}$ vaginal, así como durante la menstruación, la ovulación o el período postcoital. Se puede observar leucorrea abundante (42\%), espumosa y burbujeante de color amarillo-verdoso o amarillo (50\%), fetidez $(50 \%)$ y edema o eritema (22-37\%); también puede estar presente prurito, dispareunia y disuria (29\%). En el cérvix se presenta cervicitis: "cuello afranbuezado o colpitis macularis o colpitis focal" $" 64,68$. No obstante, entre el $25-50 \%$ de las mujeres son asintomáticos ${ }^{63}$. En las mujeres, el parásito se encuentra en la vagina, la uretra y las glándulas parauretrales. La infección uretral está presente en el $90 \%$ de las mujeres infectadas, aunque la uretra es el único sitio de infección en menos del $5 \%$ de los $\operatorname{casos}^{63,65,68}$.

Factores de riesgo: La incidencia de TV es alta entre las mujeres con parejas sexuales nuevas y múltiples, o con conductas sexuales de riesgo; presencia o infección previa por otra ITS (Herpes Virus tipo 2, HIV, sífilis, VB, candidiasis, gonorrea, etc.); pobreza, prostitución, drogadicción, bajo nivel socioeconómico, encarcelación y bajo nivel educativo ${ }^{69}$.

Diagnóstico: En el diagnóstico de la TV, son de utilidad la presentación clínica (a la especuloscopía, se puede observar eritema vaginal y cervical: "vagina en empedrado" y "cérvix en fresa"), debido a la dilatación de los capilares y a las hemorragias puntiformes; sin embargo, el diagnóstico clínico no es específico, siendo necesaria la confirmación de laboratorio, ya sea mediante el estudio en fresco, citología vaginal, cultivo, pruebas serológicas y técnicas de amplificación de ácidos nucleicos $(\text { TAAN })^{70}$.

El examen en fresco del exudado vaginal muestra tricomonas móviles (sensibilidad del 62-92\% y especificidad del 98\%), mientras que las técnicas de cultivo se utilizan ampliamente para el diagnóstico ${ }^{71}$ (tabla 7). En las mujeres sintomáticas sospechosas de tricomoniasis, pero sin tricomonas móviles

Tabla 7. Sensibilidad y Especificidad de los diferentes métodos de diagnóstico de la tricomoniasis vaginal

\begin{tabular}{lll}
\hline Métodos & Sensibilidad (\%) & Especificidad (\%) \\
\hline CCV & $60-96$ & $98-100$ \\
Clínica & 71 & 84 \\
Cultivo & $44-97$ & 100 \\
Estudio al Fresco & $9,7-71,43$ & $88,1-100$ \\
Prueba Serológicas & $55-99$ & $92-100$ \\
TAAN & $43,6-100$ & $98,2-100$ \\
\hline
\end{tabular}

CCV: Citología Cervicovaginal; TAAN: Técnicas de Amplificación de Ácidos Nucleicos 
observables, se recomienda el cultivo. El cultivo se consideró por mucho tiempo el "estándar de oro", pero las pruebas moleculares han demostrado tener una mayor sensibilidad. Por otro lado, también se encuentran disponibles métodos de inmunoensayo enzimático, amplificación de ácidos nucleicos e inmunofluorescencia ${ }^{72,73}$; donde las técnicas de amplificación de ácidos nucleicos (TAAN), son consideradas como el "Gold Standard" en el diagnóstico de la TV ${ }^{70}$.

Las TAAN pueden detectar ADN de TV en hisopos vaginales o endocervicales y en muestras de orina, con una sensibilidad entre el $88-97 \%$ y especificidad entre el $98-99 \%$. Esta debe ser la prueba preferida cuando los recursos así lo permitan ${ }^{69,72}$.

Tratamiento: Todas las mujeres diagnosticadas de tricomoniasis vaginal deben ser tratadas, independientemente de que existan manifestaciones clínicas o no; a pesar de que se han descrito tasas de curación espontánea del orden de 20 a $25 \%$. Las Trichomonas son muy sensibles al metronidazol (tabla 8), logrando una curación del 95\%; por otra parte, las parejas sexuales también deben recibir tratamiento. A pesar del uso generalizado de estos agentes antitricomonales, la resistencia ha sido relativamente rara $y$, en general, se ha manejado con dosis más $\operatorname{altas}^{74,75}$.

Se requiere tratamiento antibiótico sistémico debido a la alta frecuencia de infección de la uretra y las glándulas parauretrales en las mujeres; es por eso que el gel de metronidazol no se recomienda, ya que es menos eficaz al oral, al no alcanzar niveles terapéuticos en la uretra y en las glándulas parauretrales $^{74}$.

Complicaciones: la TV se asocia con ruptura prematura de membrana, parto prematuro, recién nacido de bajo peso, enfermedad pélvica inflamatorio atípica, infertilidad, riesgo de adquirir otra ITS (HIV, HPV, HVS, Chlamydia trachomatis, gonorrea, etc.), y riesgo de desarrollar cáncer del cuello uterino $68,69,74$.

\section{Vaginitis mixta}

La vaginitis mixta se define como la presencia simultánea de al menos dos patógenos vaginales diferentes, ambos contribuyendo a un medio vaginal anormal que conduce a signos y síntomas. Más del $20 \%$ de los casos de vaginitis infecciosa pueden ser mixtas; sin embargo, las tasas de coinfección por 2 o más organismos pueden estar entre el 20-25\%; aproximadamente el $20-30 \%$ de las mujeres con VB están coinfectadas por la Cándida spp., también se informa de la coexistencia de patógenos bacterianos y Trichomonas vaginalis (tasas de coinfección del 6080\%). La sensibilidad de los criterios de Amsel en mujeres con VB disminuye cuando la Trichomonas vaginalis y/o Cándida spp., están presentes ${ }^{21,46,52}$.

En mujeres con vaginitis mixta, el nifuratel arrojó tasas de recuperación significativamente altas a la dosis de $500 \mathrm{mg}$, siendo del $88,89 \%$ en presencia de VB; $76,92 \%$ en CVV y $90,91 \%$ en $\mathrm{TV}^{76}$.

El nifuratel, un derivado de nitrofuranos ha demostrado un amplio espectro antimicrobiano y antiprotozoario; con fuerte actividad contra Trichomonas vaginalis, Entamoeba histolytica, Giardia lamblia y Cándida spp., Gardnerella vaginalis y amplio espectro de acción antibacteriana (contra bacterias Gram positivas y Gram negativas $)^{77,78}$. Su mecanismo de acción interfiere en varios procesos enzimáticos implicados en la respiración celular, metabolismo glucídico y síntesis de la pared del microorganismo; lo que lo convierte en un buen candidato para el tratamiento de primera línea de la $\mathrm{VB}^{78}$. No sólo ha demostrado ser útil en la erradicación de las bacterias asociadas a la VB (Gardnerella vaginalis y Atopobium vaginae), sino que también fomentan el desarrollo de especies de Lactobacillus distintos al iners ${ }^{76,79,80}$.

\section{DISCUSIÓN}

En el presente estudio se ha realizado una revisión sistemática de la literatura para evaluar el síndrome de flujo vaginal (vaginitis / vaginosis), así como su actualización diagnóstica y terapéutica, en mujeres en edad reproductiva. Los frotis en fresco podrían ser útiles para el diagnóstico de la vaginitis / vaginosis (VB, CVV y TV) en determinadas situaciones clínicas; sin embargo, existen métodos de detección que gozan de mayor sensibilidad y especificidad, como las técnicas de amplificación de ácidos nucleicos (TAAN).

La mayoría de los expertos consideran que hasta el $90 \%$ de los casos de síndrome de flujo vaginal, son secundarios a vaginosis bacteriana (VB), candidiasis vulvovaginal (CVV) y tricomoniasis vaginal (TV), con

Tabla 8. Tratamientos recomendados para la tricomoniasis vaginal

\begin{tabular}{ll}
\hline Regímenes recomendados & Régimen alternativo \\
\hline $\begin{array}{l}\text { Metronidazol } 2 \text { gramos, vía oral en una sola dosis } \\
\text { ó }\end{array}$ & $\begin{array}{l}\text { Metronidazol } 500 \text { mg, vía oral dos veces } \\
\text { al día durante } 7 \text { días }\end{array}$ \\
\hline Tinidazol 2 gramos, vía oral en una sola dosis & \\
\hline
\end{tabular}


una prevalencia estimada de VB que oscila entre $9-50 \%$, pudiendo llegar al $70 \%$ en trabajadoras sexuales ${ }^{35,45,81}$.

En los Estados Unidos, la VB es actualmente la causa más común de síndrome de flujo vaginal, representando más del $30 \%$ de los casos en mujeres en edad fértil ${ }^{82}$; datos que contrastan con los reportes de Europa, cuya prevalencia es mucho más baja, siendo del $13,7 \%$ en Dinamarca $^{83}$ y $5,9 \%$ en Irlanda ${ }^{84}$.

La tasa de colonización genital por Cándida spp., varía desde el $20 \%$ en mujeres jóvenes asintomáticas hasta el $30 \%$ en gestantes ${ }^{85}$. La CVV es el resultado de Cándida albicans en el $85-95 \%$ de los casos, mientras que la tasa de incidencia de Cándida no albicans en mujeres embarazadas y no embarazadas es inferior al $10 \%{ }^{20}$.

En la tricomoniasis vaginal, en los Estados Unidos, dos estudios poblacionales que utilizaron pruebas de PCR, encontraron tasas del $2,3 \%$ entre los adolescentes ${ }^{86}$ y $3,1 \%$ entre las mujeres de 14-49 años ${ }^{87}$.

De las mujeres que buscan atención médica por síntomas de síndrome de flujo vaginal, más de la mitad suelen tener una afección diagnosticada por laboratorio; de las cuales $34 \%$ son CVV, $30 \%$ VB y $7 \%$ $\mathrm{TV}^{88}$. De lo anterior surge la recomendación de realizar tratamiento sindrómico, al ser rápido, sencillo, rentable y orientado a los problemas, logrando una alta tasa de curación y cobertura de la población de los gérmenes patógenos más frecuentes ${ }^{89,90}$.

En el tratamiento de la CVV episódica todos los regímenes tienen al menos un $80 \%$ de eficacia para fines clínicos y resultados micológicos ${ }^{21}$. En la infección recurrente, el fluconazol es la primera línea terapéutica con numerosos regímenes de tratamiento ${ }^{5}$.

El tratamiento de la VB puede ser oral o intravaginal; sin embargo, algunos estudios sugieren tasas de curación más altas con siete días de tratamiento oral de metronidazol, pero con mayor tasa de efectos adversos ${ }^{62}$; pero hasta un $50 \%$ de las mujeres tendrán una recurrencia en el próximo año, sin que existan tratamientos definitivos para la vaginosis bacteriana recurrente ${ }^{45}$.

La TV es una infección de transmisión sexual, cuyo tratamiento con una dosis única de 2 gramos de metronidazol o $400 \mathrm{mg}$ dos veces al día durante 5-7 días, junto al tratamiento de la pareja, suelen ser suficientes para su curación ${ }^{66,68}$.

En el tratamiento de la vaginitis mixta, nifuratel ha demostrado eficacia y seguridad, con pocos o nulos efectos adversos ${ }^{79,80}$. La combinación nifuratelnistatina goza de un amplio espectro antimicrobiano, razón por la cual es utilizada para el tratamiento de infecciones vaginales mixtas causadas por al menos dos de los agentes patógenos de la tríada (hongos, bacterias y $\mathrm{T}$. vaginalis $)^{91,92}$.

El síndrome de flujo vaginal, se ha asociado con secuelas graves; tales como aumento del riesgo de parto prematuro y aborto espontáneo; además puede aumentar la transmisión del virus de la inmunodeficiencia humana $(\mathrm{VIH})$, entre otras ${ }^{17,28,37}$; lo cual obliga al uso de una terapia que garantice una amplia gama de acciones antimicrobianas con un alivio sintomático rápido y notable, en especial en las pacientes con infecciones vaginales mixtas de origen bacteriano, fúngico y/o protozoario ${ }^{90}$. Las características anteriores se cumplen con la combinación de nifuratel-nistatina, ya que se mantiene la actividad antibacteriana y antiprotozoaria del nifuratel, y se potencia la actividad antimicótica de la nistatina, con la ventaja de no afectar a los lactobacilos ${ }^{92,93}$.

A pesar de la amplia revisión del presente estudio, para establecer la más actualizada información acerca del síndrome de flujo vaginal, su valor para considerarlo como una guía de manejo sigue siendo limitado. Por lo tanto, se recomiendan estudios de diferentes poblaciones y regiones, para lograr un análisis integral, tanto de los métodos diagnósticos como terapéuticos.

En conclusión, el estudio ha demostrado claramente el hecho de que es alta la prevalencia y recurrencia de la vaginitis / vaginosis, convirtiéndose en un problema común entre las mujeres en edad reproductiva. Después de la evaluación clínica, es posible que se necesiten de estudios de laboratorio a fin de hacer el adecuado diagnóstico y establecer el más conveniente tratamiento. Se deben realizar investigaciones para lograr establecer y estandarizar tanto los métodos diagnósticos como líneas de tratamiento, a fin de evitar las potenciales y graves complicaciones en los genitales de las mujeres en edad reproductiva.

\section{AGRADECIMIENTOS}

Nos gustaría agradecer al doctor David Vásquez Awad y a la doctora Adriana Patricia Camero Lascano, por su apoyo y asistencia en la elaboración de esta revisión.

Financiamiento: Autofinanciado.

Declaración de conflictos de intereses: El autors declara no tener conflicto de interés.

\section{REFERENCIAS BIBLIOGRÁFICAS}

1) George R, Thomas K, Thyagarajan SP, Jeyaseelan L, Peedicayil A, Jeyaseelan V, et al. Genital syndromes and syndromic management of vaginal discharge in a community setting. Int J STD AIDS. 2004; 15(6):367-70. http://dx.doi. org/10.1258/095646204774195191 
2) Gunther LS, Martin s HP, Gimenes F, Abreu AL, Consolaro $\mathrm{ME}$, Svidzinski TI. Prevalence of Candida albicans and non-albicans isolates from vaginal secretions: comparative evaluation of colonization, vaginal candidiasis and recurent vaginal candidiasis in diabetic and non-diabetic women. Sao Paulo Med J. 2014; 132(2):116-20. http://dx.doi. org/10.1590/1516-3180.2014.1322640

3) Ray K, Muralidhar S, Bala M, Kumari M, Salhan S, Gupta $\mathrm{SM}$, et al. Comparative study of syndromic and etiological diagnosis of reproductive tract infections/sexually transmitted infections in women in Delhi. Int J Infect Dis. 2009; 13(6):e352-9. http://dx.doi.org/10.1016/j.ijid.2008.11.021

4) Råssjö EB, Kambugu F, Tumwesigye MN, Tenywa T, Darj E. Prevalence of sexually transmitted infections among adolescents in Kampala, Uganda, and theoretical models for improving syndromic management. J Adolesc Health. 2006; 38(3):213-21. http://dx.doi.org/10.1016/j.jadohealth.2004.10.011

5) Paladine $H$, Desai U. Vaginitis: Diagnosis and Treatment. Am Fam Physician. 2018; 97(5):321-9.

6) Mlisana K, Naicker N, Werner L, Roberts L, van Loggerenberg $\mathrm{F}$, Baxter $\mathrm{C}$, et al. Symptomatic vaginal discharge is a poor predictor of sexually transmitted infections and genital tract inflammation in high-risk women in South Africa. J Infect Dis. 2012; 206(1):6-14. http://dx.doi.org/10.1093/infdis/jis298

7) Workowski KA, Bolan GA; Centers for Disease Control and Prevention. Sexually transmitted diseases treatment guidelines, 2015. MMWR Recomm Rep. 2015 Jun 5;64(RR-03):1137. Erratum in: MMWR Recomm Rep. 2015; 64(33):924.

8) Sobel JD. Vaginitis. N Engl J Med. 1997; 337(26):1896-903. http://dx.doi.org/10.1056/NEJM199712253372607

9) Bilardi JE, Walker S, Temple-Smith M, McNair R, Mooney-Somers J, Bellhouse $\mathrm{C}$, et al. The burden of bacterial vaginosis: women's experience of the physical, emotional, sexual and social impact of living with recurrent bacterial vaginosis. PLoS One. 2013; 8(9):e74378. http://dx.doi. org/10.1371/journal.pone.0074378

10) Ehrström S, Kornfeld D, Rylander E. Perceived stress in women with recurrent vulvovaginal candidiasis. J Psychosom Obstet Gynaecol. 2007; 28(3):169-76. http://dx.doi. org/10.1080/01674820601168176

11) Anderson MR, Klink K, Cohrssen A. Evaluation of vaginal complaints. JAMA. 2004; 291(11):1368-79. http://dx.doi. org/10.1001/jama.291.11.1368

12) van Schalkwyk J, Yudin MH; INFECTIOUS DISEASE COMMITTEE. Vulvovaginitis: screening for and management of trichomoniasis, vulvovaginal candidiasis, and bacterial vaginosis. J Obstet Gynaecol Can. 2015; 37(3):266-74. http:// dx.doi.org/10.1016/S1701-2163(15)30316-9

13) Witkin SS, Inglis SR, Polaneczky M. Detection of Chlamydia trachomatis and Trichomonas vaginalis by polymerase chain reaction in introital specimens from pregnant women. Am J Obstet Gynecol. 1996; 175(1):165-7. http://dx.doi. org/10.1016/s0002-9378(96)70268-5

14) Mayaud P, Mabey D. Approaches to the control of sexually transmitted infections in developing countries: old problems and modern challenges. Sex Transm Infect. 2004; 80(3):174-82. http://dx.doi.org/10.1136/sti.2002.004101

15) Altas M, Aras M, Serarslan $Y$, Davran R, Evirgen O, Yilmaz N. A medically treated multiple cerebral hydatid cyst disease. J Neurosurg Sci. 2010; 54(2):79-82.

16) Sinan O, Kaplan S, Sahin S, Peksoy S. Assessment of the effectiveness of genital infection awareness training provided to women based on the IMB model. Year: 2020; 23(3):408-15.

17) Sobel JD, Kapernick PS, Zervos M, Reed BD, Hooton T, Soper D, et al. Treatment of complicated Candida vaginitis: comparison of single and sequential doses of fluconazole. Am J Obstet Gynecol. 2001; 185(2):363-9. http://dx.doi. org/10.1067/mob.2001.115116
18) Cassone A. Vulvovaginal Candida albicans infections: pathogenesis, immunity and vaccine prospects. BJOG. 2015; 122(6):785-94. http://dx.doi.org/10.1111/1471-0528.12994

19) Fidel PL Jr. History and update on host defense against vaginal candidiasis. Am J Reprod Immunol. 2007; 57(1):2-12. http://dx.doi.org/10.1111/j.1600-0897.2006.00450.x

20) Sobel JD. Vulvovaginal candidosis. Lancet. 2007; 369(9577):1961-71. http://dx.doi.org/10.1016/S01406736(07)60917-9

21) Young GL, Jewell D. Topical treatment for vaginal candidiasis (thrush) in pregnancy. Cochrane Database Syst Rev. 2001;(4):CD000225. http://dx.doi.org/10.1002/14651858.CD000225

22) Tobin MJ. Vulvovaginal candidiasis: topical vs. oral therapy. Am Fam Physician. 1995; 51(7):1715-20, 1723-4.

23) Cassone A. Vulvovaginal Candida albicans infections: pathogenesis, immunity and vaccine prospects. BJOG. 2015; 122(6):785-94. http://dx.doi.org/10.1111/1471-0528.12994

24) Achkar JM, Fries BC. Candida infections of the genitourinary tract. Clin Microbiol Rev. 2010; 23(2):253-73. http://dx.doi. org/10.1128/CMR.00076-09

25) Mendling W, Brasch J, Cornely OA, Effendy I, Friese K, Ginter-Hanselmayer $G$, et al. Guideline: vulvovaginal candidosis (AWMF 015/072), S2k (excluding chronic mucocutaneous candidosis). Mycoses. 2015; 58 Suppl 1:1-15. http:// dx.doi.org/10.1111/myc. 12292

26) Pappas PG, Kauffman CA, Andes DR, Clancy CJ, Marr KA, Ostrosky-Zeichner L, et al. Clinical Practice Guideline for the Management of Candidiasis: 2016 Update by the Infectious Diseases Society of America. Clin Infect Dis. 2016; 62(4):e1-50. http://dx.doi.org/10.1093/cid/civ933

27) Bradshaw CS, Morton AN, Garland SM, Morris MB, Moss LM, Fairley CK. Higher-risk behavioral practices associated with bacterial vaginosis compared with vaginal candidiasis. Obstet Gynecol. 2005; 106(1):105-14. http://dx.doi. org/10.1097/01.AOG.0000163247.78533.7b

28) Centers for Disease Control and Prevention, Workowski KA, Berman SM. Sexually transmitted diseases treatment guidelines, 2006. MMWR Recomm Rep. 2006 Aug 4;55(RR-11):1-94. Erratum in: MMWR Recomm Rep. 2006; 55(36):997.

29) Bradshaw CS, Morton AN, Garland SM, Morris MB, Moss LM, Fairley CK. Higher-risk behavioral practices associated with bacterial vaginosis compared with vaginal candidiasis. Obstet Gynecol. 2005; 106(1):105-14. http://dx.doi. org/10.1097/01.AOG.0000163247.78533.7b

30) Abbott J. Clinical and microscopic diagnosis of vaginal yeast infection: a prospective analysis. Ann Emerg Med. 1995; 25(5):587-91. http://dx.doi.org/10.1016/s01960644(95)70168-0

31) Bro $F$. The diagnosis of candida vaginitis in general practice. Scand J Prim Health Care. 1989; 7(1):19-22. http://dx.doi. org/10.3109/02813438909103665

32) Hopwood V, Warnock DW, Milne JD, Crowley T, Horrocks CT, Taylor PK. Evaluation of a new slide latex agglutination test for diagnosis of vaginal candidosis. Eur J Clin Microbiol. 1987; 6(4):392-4. http://dx.doi.org/10.1007/BF02013092

33) Evans EG, Lacey CJ, Carney JA. Criteria for the diagnosis of vaginal candidosis: evaluation of a new latex agglutination test. Eur J Obstet Gynecol Reprod Biol. 1986; 22(56):365-71. http://dx.doi.org/10.1016/0028-2243(86)90127-9

34) Sulaiman MZ, Partington PE, Kinghorn GR. Use of slide latex agglutination test for rapid diagnosis of vaginal candidosis. Genitourin Med. 1987; 63(5):344-5. http://dx.doi. org/10.1136/sti.63.5.344-a

35) Sobel JD, Schmitt C, Meriwether C. A new slide latex agglutination test for the diagnosis of acute Candida vaginitis. Am J Clin Pathol. 1990; 94(3):323-5. http://dx.doi.org/10.1093/ajcp/94.3.323 
36) Hopwood V, Poulain D, Fortier B, Evans G, Vernes A. A monoclonal antibody to a cell wall component of Candida albicans. Infect Immun. 1986; 54(1):222-7. http://dx.doi. org/10.1128/IAI.54.1.222-227.1986

37) ACOG Committee on Practice Bulletins--Gynecology. ACOG Practice Bulletin. Clinical management guidelines for obstetrician-gynecologists, Number 72, May 2006: Vaginitis. Obstet Gynecol. 2006; 107(5):1195-1206. http://dx.doi. org/10.1097/00006250-200605000-00049

38) Kotarski J, Drews K, Maleszka R, Rechberger T, Woroń J, Tomaszewski J; Expert Board of Polish Gynecological Society. Stanowisko zespołu ekspertów Polskiego Towarzystwa Ginekologicznego w sprawie leczenia ostrego i nawrotwege grzybiczego zapalenia pochwy i sromu--stan wiedzy na 2008 rok [Treatment of acute and recurrent vulvovaginal candidiasis (VVC/rVVC)--state of art in 2008. Expert Board of Polish Gynecological Society]. Ginekol Pol. 2008; 79(9):638-52.

39) Peters BM, Yano J, Noverr MC, Fidel PL Jr. Candida vaginitis: when opportunism knocks, the host responds. PLoS Pathog. 2014; 10(4):e1003965. http://dx.doi.org/10.1371/ journal.ppat.1003965

40) Salehei Z, Seifi Z, Mahmoudabadi A. Sensitivity of Vaginal Isolates of Candida to Eight Antifungal Drugs Isolated From Ahvaz, Iran, Jundishapur J Microbiol. 2012; 5(4):574-7. http://dx.doi.org/10.5812/jjm.4556

41) Hill GB. The microbiology of bacterial vaginosis. Am J Obstet Gynecol. 1993; 169(2 Pt 2):450-4. http://dx.doi.org/10.1016/0002-9378(93)90339-k

42) Marrazzo JM, Martin DH, Watts DH, Schulte J, Sobel JD, Hillier SL, et al. Bacterial vaginosis: identifying research gaps proceedings of a workshop sponsored by $\mathrm{DHHS} / \mathrm{NIH} /$ NIAID. Sex Transm Dis. 2010; 37(12):732-44. http://dx.doi. org/10.1097/OLQ.0b013e3181fbbc95

43) van de Wijgert JH, Borgdorff $H$, Verhelst $R$, Crucitti T, Francis $\mathrm{S}$, Verstraelen $\mathrm{H}$, et al. The vaginal microbiota: what have we learned after a decade of molecular characterization? PLoS One. 2014; 9(8):e105998. http://dx.doi.org/10.1371/ journal.pone.0105998

44) Allsworth JE, Peipert JF. Prevalence of bacterial vaginosis: 2001-2004 National Health and Nutrition Examination Survey data. Obstet Gynecol. 2007; 109(1):114-20. http:// dx.doi.org/10.1097/01.AOG.0000247627.84791.91

45) Koumans EH, Sternberg M, Bruce C, McQuillan G, Kendrick J, Sutton M, et al. The prevalence of bacterial vaginosis in the United States, 2001-2004; associations with symptoms, sexual behaviors, and reproductive health. Sex Transm Dis. 2007; 34(11):864-9. http://dx.doi.org/10.1097/ OLQ.0b013e318074e565

46) Coleman JS, Gaydos CA. Molecular Diagnosis of Bacterial Vaginosis: an Update. J Clin Microbiol. 2018; 56(9):e0034218. http://dx.doi.org/10.1128/JCM.00342-18

47) Verstraelen $H$, Verhelst $R$, Vaneechoutte $M$, Temmerman $M$. The epidemiology of bacterial vaginosis in relation to sexual behaviour. BMC Infect Dis. 2010; 10:81. http://dx.doi. org/10.1186/1471-2334-10-81

48) Neggers $Y H$, Nansel TR, Andrews WW, Schwebke JR, Yu $\mathrm{KF}$, Goldenberg RL, et al. Dietary intake of selected nutrients affects bacterial vaginosis in women. J Nutr. 2007; 137(9):2128-33. http://dx.doi.org/10.1093/jn/137.9.2128

49) Eschenbach DA, Hillier S, Critchlow C, Stevens C, DeRouen T, Holmes KK. Diagnosis and clinical manifestations of bacterial vaginosis. Am J Obstet Gynecol. 1988; 158(4):819-28. http://dx.doi.org/10.1016/0002-9378(88)90078-6

50) Amsel R, Totten PA, Spiegel CA, Chen KC, Eschenbach D, Holmes KK. Nonspecific vaginitis. Diagnostic criteria and microbial and epidemiologic associations. Am J Med. 1983; 74(1):14-22. http://dx.doi.org/10.1016/00029343(83)91112-9
51) Nugent RP, Krohn MA, Hillier SL. Reliability of diagnosing bacterial vaginosis is improved by a standardized method of gram stain interpretation. J Clin Microbiol. 1991; 29(2):297301. http://dx.doi.org/10.1128/JCM.29.2.297-301.1991

52) Schwebke JR, Hillier SL, Sobel JD, McGregor JA, Sweet $\mathrm{RL}$. Validity of the vaginal gram stain for the diagnosis of bacterial vaginosis. Obstet Gynecol. 1996; 88(4 Pt 1):573-6. http://dx.doi.org/10.1016/0029-7844(96)00233-5

53) Sha BE, Chen HY, Wang QJ, Zariffard MR, Cohen MH, Spear GT. Utility of Amsel criteria, Nugent score, and quantitative PCR for Gardnerella vaginalis, Mycoplasma hominis, and Lactobacillus spp. for diagnosis of bacterial vaginosis in human immunodeficiency virus-infected women. J Clin Microbiol. 2005; 43(9):4607-12. http://dx.doi.org/10.1128/ JCM.43.9.4607-4612.2005

54) Bradshaw CS, Morton AN, Garland SM, Horvath LB, Kuzevska I, Fairley CK. Evaluation of a point-of-care test, BV Blue, and clinical and laboratory criteria for diagnosis of bacterial vaginosis. J Clin Microbiol. 2005; 43(3):1304-8. http://dx.doi.org/10.1128/JCM.43.3.1304-1308.2005

55) Myziuk L, Romanowski B, Johnson SC. BV Blue test for diagnosis of bacterial vaginosis. J Clin Microbiol. 2003; 41(5):1925-8. http://dx.doi.org/10.1128/jcm.41.5.19251928.2003

56) West B, Morison L, Schim van der Loeff M, Gooding E, Awasana AA, Demba E, et al. Evaluation of a new rapid diagnostic kit (FemExam) for bacterial vaginosis in patients with vaginal discharge syndrome in The Gambia. Sex Transm Dis. 2003; 30(6):483-9. http://dx.doi.org/10.1097/00007435200306000-00003

57) Fredricks DN, Fiedler TL, Thomas KK, Oakley BB, Marrazzo JM. Targeted PCR for detection of vaginal bacteria associated with bacterial vaginosis. J Clin Microbiol. 2007; 45(10):3270-6. http://dx.doi.org/10.1128/JCM.01272-07

58) Hilbert DW, Smith WL, Chadwick SG, Toner G, Mordechai E, Adelson ME, et al. Development and Validation of a Highly Accurate Quantitative Real-Time PCR Assay for Diagnosis of Bacterial Vaginosis. J Clin Microbiol. 2016; 54(4):101724. http://dx.doi.org/10.1128/JCM.03104-15

59) Patterson JL, Girerd PH, Karjane NW, Jefferson KK. Effect of biofilm phenotype on resistance of Gardnerella vaginalis to hydrogen peroxide and lactic acid. Am J Obstet Gynecol. 2007; 197(2):170.e1-7. http://dx.doi.org/10.1016/j. ajog.2007.02.027

60) Swidsinski A, Mendling W, Loening-Baucke V, Swidsinski S, Dörffel Y, Scholze J, et al. An adherent Gardnerella vaginalis biofilm persists on the vaginal epithelium after standard therapy with oral metronidazole. Am J Obstet Gynecol. 2008; 198(1):97.e1-6. http://dx.doi.org/10.1016/j. ajog.2007.06.039

61) Machado D, Castro J, Palmeira-de-Oliveira A, Martinez-de-Oliveira J, Cerca N. Bacterial Vaginosis Biofilms: Challenges to Current Therapies and Emerging Solutions. Front Microbiol. 2016; 6:1528. http://dx.doi.org/10.3389/fmicb.2015.01528

62) Menard JP. Antibacterial treatment of bacterial vaginosis: current and emerging therapies. Int $\mathrm{J}$ Womens Health. 2011; 3:295-305. http://dx.doi.org/10.2147/IJWH.S23814

63) Hobbs MM, Lapple DM, Lawing LF, Schwebke JR, Cohen MS, Swygard H, et al. Methods for detection of Trichomonas vaginalis in the male partners of infected women: implications for control of trichomoniasis. J Clin Microbiol. 2006; 44(11):3994-9. http://dx.doi.org/10.1128/JCM.00952-06

64) Schwebke JR, Burgess D. Trichomoniasis. Clin Microbiol Rev. 2004; 17(4):794-803, table of contents. http://dx.doi. org/10.1128/CMR.17.4.794-803.2004

65) Rathod SD, Krupp K, Klausner JD, Arun A, Reingold AL, Madhivanan P. Bacterial vaginosis and risk for Trichomonas 
vaginalis infection: a longitudinal analysis. Sex Transm Dis. 2011; 38(9):882-6. http://dx.doi.org/10.1097/OLQ.0b013e$31821 \mathrm{f9} 1 \mathrm{a} 1$

66) Garrett NJ, Osman F, Maharaj B, Naicker N, Gibbs A, Norman $E$, et al. Beyond syndromic management: Opportunities for diagnosis-based treatment of sexually transmitted infections in low- and middle-income countries. PLoS One. 2018; 13(4):e0196209. http://dx.doi.org/10.1371/journal. pone.0196209

67) World Health Organization. Global incidence and prevalence of selected curable sexually transmitted infections 2008. 1. Sexually transmitted diseases - epidemiology. 2. Chlamydia trachomatis. 3. Neisseria gonorrhea 4. Syphilis. 5. Trichomonas vaginalis I. http://apps.who.int/iris/bitstream/ handle/10665/75181/9789241503839_eng.

70) Krieger JN, Tam MR, Stevens CE, Nielsen IO, Hale J, Kiviat NB, et al. Diagnosis of trichomoniasis. Comparison of conventional wet-mount examination with cytologic studies, cultures, and monoclonal antibody staining of direct specimens. JAMA. 1988; 259(8):1223-7. http://dx.doi. org/10.1001/jama.259.8.1223

71) Stary A, Kuchinka-Koch A, Teodorowicz L. Detection of Trichomonas vaginalis on modified Columbia agar in the routine laboratory. J Clin Microbiol. 2002; 40(9):3277-80. http:// dx.doi.org/10.1128/jcm.40.9.3277-3280.2002

72) Andrea SB, Chapin KC. Comparison of Aptima Trichomonas vaginalis transcription-mediated amplification assay and BD affirm VPIII for detection of $\mathrm{T}$. vaginalis in symptomatic women: performance parameters and epidemiological implications. J Clin Microbiol. 2011; 49(3):866-9. http://dx.doi. org/10.1128/JCM.02367-10.

73) Owen MK, Clenney TL. Management of vaginitis. Am Fam Physician. 2004; 70(11):2125-32.

74) Forna F, Gülmezoglu AM. Interventions for treating trichomoniasis in women. Cochrane Database Syst Rev. 2003; (2):CD000218. http://dx.doi.org/10.1002/14651858. CD000218

75) Kissinger P. Trichomonas vaginalis: a review of epidemiologic, clinical and treatment issues. BMC Infect Dis. 2015; 15:307. http://dx.doi.org/10.1186/s12879-015-1055-0

76) Liang Q, Li N, Song S, Zhang A, Li N, Duan Y. High-dose nifuratel for simple and mixed aerobic vaginitis: A single-center prospective open-label cohort study. J Obstet Gynaecol Res. 2016; 42(10):1354-1360. http://dx.doi.org/10.1111/ jog. 13052

77) Coppi F, Bertagnolli V. Esperienze cliniche in urologia con il metilmercadone nuovo chemioterapico furanico. Urologia. 1965; 32:678-83. https://doi. org/10.1177/039156036503200605

78) Dubini F, Furneri P. Attività antimicrobica del nifuratel. G. Ital. Chemioter. 1985; 32:545-552.

79) Togni G, Battini V, Bulgheroni A, Mailland F, Caserini M, Mendling $\mathrm{W}$. In vitro activity of nifuratel on vaginal bacteria: could it be a good candidate for the treatment of bacterial vaginosis? Antimicrob Agents Chemother. 2011; 55(5):2490-2. http://dx.doi.org/10.1128/AAC.01623-10

80) Mendling W, Poli A, Magnani P. Clinical effects of nifuratel in vulvovaginal infections. A meta-analysis of metronidazole-controlled trials. Arzneimittelforschung. 2002; 52(10):72530. http://dx.doi.org/10.1055/s-0031-1299958

81) Johnson LF, Coetzee DJ, Dorrington RE. Sentinel surveillance of sexually transmitted infections in South Africa: a review. Sex Transm Infect. 2005; 81(4):287-93. http://dx.doi. org/10.1136/sti.2004.013904

82) Simhan HN, Bodnar LM, Krohn MA. Paternal race and bacterial vaginosis during the first trimester of pregnancy. Am J Obstet Gynecol. 2008; 198(2):196.e1-4. http://dx.doi.org/10.1016/j.ajog.2007.09.006
83) Thorsen P, Vogel I, Molsted K, Jacobsson B, Arpi M, Møller $B R$, Jeune $B$. Risk factors for bacterial vaginosis in pregnancy: a population-based study on Danish women. Acta Obstet Gynecol Scand. 2006; 85(8):906-11. http://dx.doi. org/10.1080/00016340500432655

84) Tolosa JE, Chaithongwongwatthana S, Daly S, Maw WW, Gaitán H, Lumbiganon P, et al. The International Infections in Pregnancy (IIP) study: variations in the prevalence of bacterial vaginosis and distribution of morphotypes in vaginal smears among pregnant women. Am J Obstet Gynecol. 2006; 195(5):1198-204. http://dx.doi.org/10.1016/j. ajog.2006.08.016

85) Gonçalves B, Ferreira C, Alves CT, Henriques M, Azeredo J, Silva S. Vulvovaginal candidiasis: Epidemiology, microbiology and risk factors. Crit Rev Microbiol. 2016; 42(6):905-27. http://dx.doi.org/10.3109/1040841X.2015.1091805

86) Miller WC, Swygard H, Hobbs MM, Ford CA, Handcock MS, Morris M, et al. The prevalence of trichomoniasis in young adults in the United States. Sex Transm Dis. 2005; 32(10):593-8. http://dx.doi.org/10.1097/01. olq.0000179874.76360.ad

87) Sutton M, Sternberg M, Koumans EH, McQuillan G, Berman $\mathrm{S}$, Markowitz L. The prevalence of Trichomonas vaginalis infection among reproductive-age women in the United States, 2001-2004. Clin Infect Dis. 2007; 45(10):1319-26. http://dx.doi.org/10.1086/522532

88) Hillier SL, Austin M, Macio I, Meyn LA, Badway D, Beigi R. Diagnosis and Treatment of Vaginal Discharge Syndromes in Community Practice Settings. Clin Infect Dis. 2020: ciaa260. http://dx.doi.org/10.1093/cid/ciaa260

89) Bosu WK. Syndromic management of sexually transmitted diseases: is it rational or scientific? Trop Med Int Health. 1999; 4(2):114-9. http://dx.doi.org/10.1046/j.13653156.1999.00360.x

90) Espitia De La Hoz FJ. Evaluación de la eficacia y seguridad del policresuleno en el trata-miento de la vaginitis mixta, Armenia, Colombia, 2017-2019. Estudio aleatorizado. Arch Med (Manizales). 2021; 21(1):45-56. https://doi. org/10.30554/archmed.21.1.3756.2020

91) Cepický P, Malina J, Kuzelová M. Terapie aerobní vaginitis a klinicky nejasných prícin vulvovaginálního diskomfortu [Treatment of aerobic vaginitis and clinically uncertain causes of vulvovaginal discomfort]. Ceska Gynekol. 2003; 68(6):439-42.

92) Polatti F, Nappi RE, Brundu B, Fantuzzi M, Frisenda L. Clinical study on the dose-effect relationship of a nifuratel-nystatin combination in the treatment of vulvo-vaginal infections. Arzneimittelforschung. 2003; 53(10):730-7. https://doi.org/10.1055/s-0031-1299819

93) Polatti F. Vaginosis bacteriana, Atopobium vaginae y nifuratel. Curr Clin Pharmacol. 2012; 7(1):36-40. https://doi. org/10.2174/157488412799218824.

\section{Correspondencia:}

Franklin José Espitia De La Hoz

Dirección: Carrera 12 \# 0 - 75, Consultorio 508 Clínica del Café

Armenia, Quindío, Colombia

E-mail: espitiafranklin@hotmail.com

Teléfono: 3127436696 